
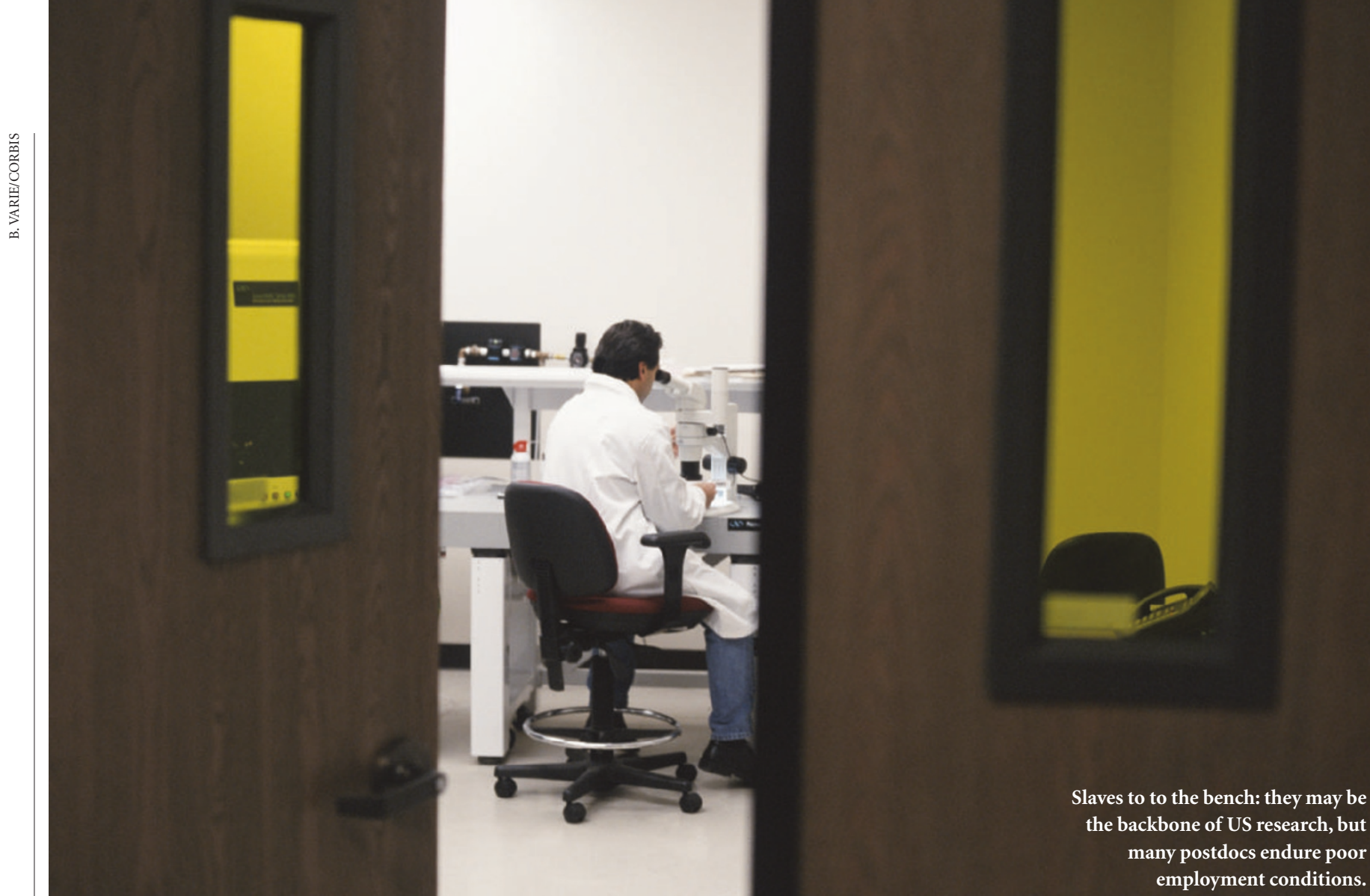

\title{
Young, gifted ... and broke
}

\section{At the turn of the millennium, the US National Academies put the spotlight on the miserable pay and conditions experienced by most US postdocs. Things are now starting to change, but slowly. Betsy Mason reports.}

L ow pay, a lack of benefits, inadequate recognition and poor career guidance. This, according to an influential report $^{1}$ released in 2000 by the US National Academies, is the lot of postdocs working in the United States. Across the country, more than 50,000 scientists and engineers make up this part of the workforce, existing at that indefinite stage of continued training between earning a $\mathrm{PhD}$ and gaining a permanent academic position.

These young researchers represent the engine room of US science, responsible for most of the hands-on work that underpins papers published each week in leading journals. And if the most talented of them are forced to quit academia for greener pastures, they will take with them the vibrancy that drives US scientific enterprise.

This week in Washington DC, the academies' Committee on Science, Engineering, and Public Policy (COSEPUP), which produced the report, is holding a conference to review progress since it thrust the problems faced by postdocs into the limelight. In some respects, the news is good. A National Postdoctoral Association (NPA) has been set up to represent postdocs' interests. Local associa- tions have sprung up at academic institutions across the country. And for some postdocs, salaries and benefits have improved.

But problems still abound. Some universities are conspicuously lagging behind in improving pay and conditions for their postdoctoral researchers. And for those postdocs - more than half of the total - who are visitors from abroad, visa restrictions imposed under the new focus on homeland security are causing serious difficulties ${ }^{2}$.

"It's a mixed bag," says Timothy Coetzee, director of research training programmes at the National Multiple Sclerosis Society, a charity that has won plaudits for its enlight-

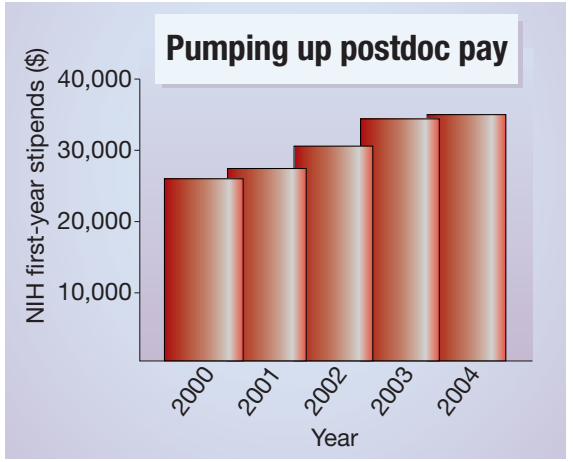

ened attitude towards career development for the postdocs supported by its grants. "We've made some progress, but we still have a long way to go."

\section{On the rise}

The National Institutes of Health (NIH), which funds more postdocs than any other agency or institution in the country, has also taken notice of the situation. "It's an issue of considerable importance to us," says Walter Schaffer, acting director of the agency's Office of Extramural Programs.

Since 2000, the NIH has increased the minimum stipend for first-year postdocs receiving its National Research Service Awards, of which some 1,800 are given out each year, by almost one-third (see Graph, left). Those funded under the scheme are also guaranteed a salary rise of about $5 \%$ with each year of experience. This is good news for other postdocs as well, because many institutions, including major research universities, are adopting the NIH pay scale ${ }^{3}$.

Another positive sign is the birth of the NPA, founded in January 2003 by a group of postdocs in the biological sciences looking for an organized voice at the national level. 


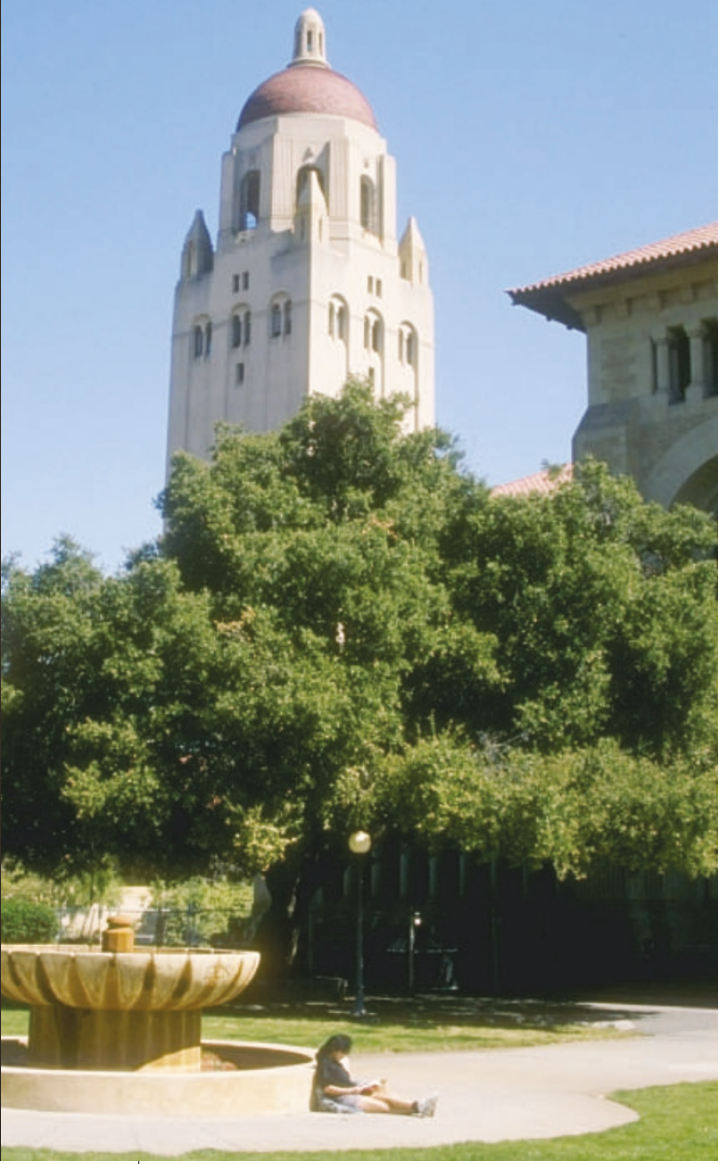

Trailblazer: Stanford University was one of the first to set up a dedicated postdoc office.

The group tackles issues such as the need for better salaries and benefits, and is trying to gather data on current institutional postdoc policies. The NPA is already being taken seriously by agencies such as the NIH, which invited the group's representatives to take part in a meeting on postdoc training and opportunities in October last year.

"This is a good time to deal with postdoc issues because everybody is interested right now, and they're listening," says Claudina Stevenson, a founding member of the NPA who works at Harvard Medical School's Dana-Farber Cancer Institute in Boston, Massachusetts.

The NPA is also helping postdocs to form local associations, and encouraging institutions to create offices that specifically deal with policies concerning postdocs. It estimates there are now more than 50 institutions with postdoc associations or offices, most of which came into existence in the past few years.

Stanford University in California was one of the pioneers, creating a postdoc office in 1989. Ten years later, its postdocs also formed their own association. Stanford's 1,300-plus postdocs enjoy salaries that are higher than the NIH minimum and have benefits that include health insurance and maternityleave. Other success stories include the Whitehead Institute for Biomedical Research in Cambridge, Massachusetts, where postdocs have dental insurance and get a supplement of $\$ 2,000$ per year to help them plan for their retirement. And at the University of North
Carolina at Chapel Hill, the local postdoc association worked with the postdoc office to establish a minimum salary and a five-year cap on the time a researcher can be employed as a postdoc - if they are kept on longer, they must be given a permanent position.

At the University of Connecticut, meanwhile, postdocs have formed a fully fledged labour union that bargains with the administration on salary and benefits. Last month, it negotiated a rise in the minimum postdoc salary from $\$ 27,000$ to $\$ 34,200$, and won annual rises, health insurance, paid sick leave and holidays, plus a standardized grievance procedure. If the Connecticut legislature doesn't object, these policies will become official next month.

But at many institutions, postdocs still toil without a guaranteed salary minimum. "Awareness of postdoc issues has definitely improved," says Helen McBride, a fifth-year postdoc in developmental biology at the California Institute of Technology in Pasadena, where the high cost of living means that the minimum salary of $\$ 32,000$ doesn't go far. "But there's still a lack of this awareness translating into change.”

\section{Second-class citizens}

Recipients of postdoctoral fellowships are often classified as 'trainees' at their host institutions, which can leave them ineligible for benefits such as healthcare. For instance, Cornelia Bentley and her husband Jeffrey Pitman, now both postdocs in molecular biology at Brown University in Providence, Rhode Island, were paying $\$ 680$ per month to insure their family of three because Pitman's fellowship from the American Cancer Society left them without health coverage. When they couldn't make ends meet, the principal investigator of Pitman's lab stepped in temporarily to cover the insurance costs until Bentley managed to secure a postdoc with benefits. "I don't know what we would have done otherwise," Bentley says.

Such problems are becoming more acute because of a congested job market that leaves too many PhDs chasing too few permanent academic positions. As a result, many researchers have to eke out a living as postdocs into their late thirties or early forties, or just give up and look for opportunities elsewhere.

More and more postdocs are switching to careers in industry, and some are leaving science altogether. After spending six years as a postdoc in genetics at the Wadsworth Center in Albany, New York, and having no luck landing a faculty position, Derek Scholes is now applying for fellowships in bioethics. "I typify many postdocs who were keen to enter a research career and for whatever reason, didn't get enough publications to be competitive," he says.

Some researchers fear that the grim job outlook, combined with poor pay and conditions, may discourage the very best students from entering science in the first place. William Zumeta, who studies education policy at the University of Washington in Seattle, has found some evidence that the best physical-sciences graduate students are opting to go to business school instead". "If you buy the idea that the best and the brightest drive scientific innovation, this could be a real problem," he says.

\section{A foreign affair}

Until recently, US researchers could count on a boundless supply of high-quality foreign scientists to fill positions in their labs. But tighter security has made it tougher for such researchers, particularly those in fields deemed sensitive by the US government, to get visas. This topic is likely to be hotly debated at this week's COSEPUP meeting.

Another live issue is the tendency of some principal investigators to view their postdocs as little more than hired hands. "There is a lack of understanding of what a postdoc is," says one evolutionary biologist, who left her first postdoc after a year when she realized her adviser was treating her like a technician.

What's needed, say postdoc activists, are policies to ensure that postdocs receive proper training and career guidance designed to aid their transition into independent researchers supervising their own students and fellows.

Some funding bodies are now providing a small number of grants with this express aim. The National Multiple Sclerosis Society awards three 'career transition fellowships' each year, which are worth about $\$ 550,000$ and consist of two years of postdoctoral funding followed by salary and research support for the first three years in a faculty position. Another research foundation, the Burroughs Wellcome Fund, has awarded 15 similar career grants since 2002. But these schemes are a drop in the ocean - many more such grants will be needed to make a difference to the academic job market. "The big problem is that policymakers don't want to take responsibility for career development," says Zumeta.

As this week's COSEPUP meeting assesses progress, the grades it marks on its report card are likely to range from A to F. Postdocs still have a long list of grievances, but at least things are moving in the right direction. "I think we've done most of the easy stuff," says Coetzee. "Now comes the hard part of deciding where to put our priorities."

Betsy Mason is a freelance writer based in New

Haven, Connecticut.

1. Enhancing the Postdoctoral Experience for Scientists and Engineers (National Academies Press, Washington DC, 2000).

2. Brumfiel, G. et al. Nature 427, 190-195 (2004).

3. Kreeger, K. Nature 427, 178-179 (2004).

4. Zumeta, W. \& Raveling, J. S. The Best and Brightest for Science: Is There a Problem Here? (Commission on Professionals in

Science and Technology, Washington DC, 2002)

\section{COSEPUP meeting}

www7.nationalacademies.org/postdoc

National Postdoctoral Association

www.nationalpostdoc.org 